\title{
NOVAS INFORMAÇÕES SOBRE GEOCRONOLOGIA EM NÍVEIS DE BAIXO TERRAÇO FLUVIAL DO RIO MOGI GUAÇU, SP, BRASIL
}

\section{NEW INFORMATION ON GEOCHRONOLOGY IN LEVELS OF THE LOW RIVER TERRACE OF RIO MOGI GUAÇU IN SÃO PAULO, BRAZIL}

\author{
Daniel Luís Storani \\ Departamento de Geografia, Universidade Estadual de Campinas \\ Rua João Pandiá Calógeras, 51, Campinas, São Paulo, CEP: 13083-870, Brasil \\ E-mail: daniel.storani@ige.unicamp.br \\ Archimedes Perez Filho \\ Departamento de Geografia, Universidade Estadual de Campinas \\ Rua João Pandiá Calógeras, 51, Campinas, São Paulo, CEP: 13083-870, Brasil \\ E-mail: archi@ige.unicamp.br
}

\section{Informações sobre o Artigo \\ Data de Recebimento: \\ 19/12/2014 \\ Data de Aprovação: \\ 23/03/2015}

\section{Palavras-chave:}

Rio Mogi Guaçu; LOE; Baixos Terraços Fluviais.

\section{Keywords:}

Mogi Guaçu River; OSL; Low River Terraces.

\begin{abstract}
Resumo:
Este trabalho visa complementar estudo inicialmente realizado por Perez Filho et al. (1980) em terraços fluviais do Rio Mogi Guaçu, na área da Fazenda Campininha, no município paulista de Mogi Guaçu. Foram coletadas amostras de coberturas superficiais que recobrem três níveis de terraços, além de amostra em pedimento adjacente. Tais amostras foram submetidas à datação absoluta através do método de Luminescência Opticamente Estimulada (LOE), que determina o período da última exposição do material sedimentar à luz do sol. Os resultados das datações apontam diferentes idades do material superficial em cada um dos três diferentes níveis de terraço do perfil, sendo o nível mais distante do rio e com maior altitude, mais velho (aproximadamente 1.900 anos), o nível denominado II, intermediário, mais novo que o superior (aproximadamente 1.150 anos) e o nível III, mais próximo ao canal fluvial, o mais recente (aproximadamente 630 anos). A cobertura do pedimento é datado com aproximadamente 3.650 anos. Esses resultados indicam a possibilidade de existência de oscilações climáticas no período pré-atual, sendo que períodos mais secos (possivelmente há 1.900, 1.150 e 630 anos) permitiriam o desenvolvimento dos níveis de terraço, com deposição de material sedimentar arenoso, enquanto que períodos mais úmidos intermediários poderiam ter causado entalhamento do canal em distintos momentos, com diferenciação de tais níveis.
\end{abstract}

\section{Abstract:}

The objective of this paper is to complement a previous study by Perez Filho et al. (1980) in fluvial terraces of Rio Mogi Guaçu, in the area of the farm Campininha, 
in Mogi Guaçu, state of São Paulo. Samples were collected from the surface of three levels of terraces, plus a sample from an adjacent pediment. These samples were submitted to absolute dating by Optically Stimulated Luminescence method (OSL), which determines the period of the last exposure of the sedimentary material to sunlight. The results of datings show different ages of the surface material in each of the three different terrace levels of the profile, being the level most distant from the river and at a higher altitude, older (approximately 1,900 years), the level named II, intermediate, younger than the upper one (approximately 1,150 years), and the level III, closer to the river channel, the most recent one (of about 630 years ago). The pediment cover is dated of approximately 3,650 years. These results indicate that climatic oscillations were possibly present in the pre-recent period, and drier periods (possibly 1,900, 1,150 and 630 years) would allow the development of terrace levels, with the deposition of sedimentary sandy material, while more humid intermediate periods could have caused carving of the channel at different times, with differentiation of the levels.

\section{Introdução}

Os métodos existentes na atualidade para análises e datação de coberturas superficiais, portanto, material de origem dos solos, permitem atribuir a períodos específicos da evolução da paisagem a origem de determinadas condições conhecidas ou modeladas. A interpretação geomorfológica das paisagens é essencial para o entendimento da seqüência de acontecimentos que atribuíram a elas determinadas características. Assim, o uso de técnicas, que se aprimoram a cada dia, corrobora ou não idéias sobre a evolução das mesmas.

De acordo com Penteado (1980), o relevo atual é marcado pelas influências dos paleoclimas devido às importantes modificações climáticas que o globo sofreu "recentemente". Bigarella et al. (1994) citam que a paisagem atual sofre influências não só das grandes mudanças climáticas, mas também das pequenas flutuações do clima.

O Quaternário pode ser caracterizado por significativa instabilidade climática. Penteado (1980) mostra que, nos últimos 20.000 anos, os climas da Terra sofreram profundas modificações. Sabe-se que as latitudes médias sofreram fenômenos periglaciais; as regiões áridas tiveram períodos chuvosos; zonas semi-áridas surgiram nas margens das zonas inter-tropicais; e na zona Equatorial variaram períodos pluviais e secos. Ao fim do Terciário, quase nenhuma região do planeta conheceu períodos de condições estáveis e evoluiu sob ação de um único sistema morfoclimático. É mais comum, portanto, encontrar hoje paisagens que evoluíram de uma forma poligênica, do ponto de vista morfoclimático, tendo traços de sistemas morfogenéticos diferentes e sucessivos.

Os geólogos americanos Damuth e Fairbridge (1970) apresentam, em um trabalho que serve de base para as discussões a respeito das condições climáticas no Brasil durante o Período Quaternário, principalmente no Pleistoceno, fundamentos para explicar as mudanças nas circulações atmosféricas e correntes oceânicas. Eles também se basearam em diversos estudos para a mesma área, principalmente em Bigarella e Andrade (1965) e Bigarella et al. (1965), os quais apresentam evidências das variações climáticas nas formas de relevo das regiões consideradas.

De acordo com Damuth e Fairbridge (1970), condições meteorológicas únicas que existiram sobre o continente sul-americano, para as fases glacial e interglacial, explicariam a alternância entre os climas úmido e semi-árido ou árido na região.

Os autores afirmam que, atualmente, e também durante as fases interglaciais, uma célula de alta pressão está semipermanentemente localizada sobre o meio do Atlântico Sul, enquanto uma célula de baixa pressão se localiza sobre a Amazônia e o interior subtropical. Monções, ventos alísios e fatores orográficos se combinam e favorecem chuvas por quase todo o ano, embora no sudeste do Brasil elas se concentrem no verão "de sul”, ou seja, entre os meses de dezembro e fevereiro.

Bigarella et al. (1994), de acordo com os estudos acima citados, demonstram que durante o Pleistoceno, nas áreas geográficas correspondentes ao território brasileiro, dois conjuntos diferentes de processos, operando alternadamente, submeteram a paisagem à evolução lateral das vertentes em clima semi-árido (épocas glaciais) ou à dissecação em clima úmido (épocas interglaciais). A ação erosiva seria, no entanto, muito efetiva no período de transição de um tipo de clima para o outro. Assim, na transição de uma fase climática para outra, devem ser levadas em consideração, além das importantes mudanças na cobertura vegetal, grandes modificações 


\section{Novas Informações Sobre Geocronologia na Planície de Inundação do Rio Mogi Guaçu, SP, Brasil}

nos vários processos atuantes. Durante o clima úmido desenvolve-se um manto de decomposição formado por alteração química, sobre o qual teria surgido a floresta. Na transição do clima úmido para o mais seco, a floresta regrediria, sendo substituída por uma cobertura vegetal menos densa e aberta, classificado como caatinga ou cerrado. Sob a cobertura de floresta, os solos estariam protegidos contra erosão acelerada, o que não aconteceria sob o novo tipo de vegetação.

Sobre a evolução da paisagem, Casseti (2005) afirma que o clima árido ou semi-árido contribui para sua evolução "horizontal”, por meio do recuo paralelo das vertentes, que alarga vales, como as calhas aluviais atuais, ou processando a destruição de formas elaboradas nos climas úmidos, chegando à condição de aplainamento extensivo, quando prevalece o clima seco por um longo tempo geológico. Já o clima úmido causaria a evolução "vertical" do relevo, promovendo o entalhamento da drenagem, que vai variar em relação à intensidade dos esforços tectônicos (compensações isostáticas, fenômenos epirogênicos ou orogênicos) ou da própria erosão remontante em função do gradiente do canal. Assim, para a região Sudeste do País, correspondentes a fases secas citadas, têm-se superfícies interplanálticas e níveis mais baixos de pedimentação e de terraços, elaborados por processos dominantes de erosão mecânica.

De acordo com Suguio (2010), para analisar a evolução geomorfológica de uma área, envolvendo as unidades morfoestratigráficas (superfícies e materiais componentes), torna-se necessário estabelecer relações de antiguidade entre elas e definir os critérios para correlaciona-las por áreas mapeáveis de escala mínima de 1:25.000.

Wolman e Leopold (1970) citam estudos de uma série de planícies de inundação em diversas regiões fisiográficas e climáticas nos Estados Unidos e na Índia, os quais demonstram que a frequência de inundações das planícies é notavelmente uniforme em cada rio nessas áreas. O que mostra como característica comum aos diversos canais a frequência de cheias.

A respeito das metodologias de análise de ambientes fluviais, Bridge (2003) demonstra que estudos sobre a origem a evolução de sistemas fluviais costumam envolver trabalhos de campo, análises de mapas e fotografias aéreas, experimentos de laboratório e modelos teóricos. No entanto, a incapacidade de fazer observações detalhadas de longo prazo sobre a origem e evolução dos sistemas fluviais em modelos geologicamente realistas tem dificultado a compreensão dos sistemas fluviais e nossa capacidade de testar modelos teóricos.

Suguio (1999) afirma que as transformações naturais processam-se em distintas escalas temporais e, assim, muitas mudanças ocorridas em dezenas, centenas ou milhares de anos não podem ser percebidas a olho nu sendo, muitas vezes, necessário recorrer ao auxílio de equipamentos de precisão e técnicas avançadas. Por outro lado, não é fácil correlacionar as modificações citadas com as que ocorrem em milhões ou bilhões de anos. Somente os estudos do Quaternário são capazes de estabelecer o elo entre o passado geologicamente pouco remoto e o presente, levando a tentar estabelecer interpretação da evolução da paisagem. Desta forma, a ciência necessita de dados globais, regionais e locais, cada vez mais confiáveis, que permitam a calibração de modelos que permitam a interpretação das oscilações climáticas recentes. Para isso, além dos dados ligados às condições atuais (da meteorologia), é necessário reconstituir a história do clima, isto é, as mudanças paleoclimáticas.

Suguio e Bigarella (1979) mostram que os terraços são frequentemente utilizados como chave na interpretação da história geológica de uma região. Mudanças ambientais levam os rios a erodirem os seus próprios depósitos previamente formados. Tais autores destacam que a literatura clássica geralmente refere estas mudanças como tectônicas, isto é, a região pode ter sido levantada ou basculada alterando o nível de base dos rios. Entretanto, mudanças muito mais importantes são devidas a modificações de clima, as quais afetam a hidrodinâmica do sistema fluvial influindo na descarga líquida ou na carga sedimentar do rio. Em regiões instáveis, como no Japão, tende-se a interpretar os terraços como resultantes de um levantamento tectônico. Demais autores afirmam que os terraços são referidos a mais recente e mais acentuada mudança climática, quando houve a passagem de um período glacial para interglacial.

Diferentes critérios, ainda segundo Suguio e Bigarella (1979), devem ser empregados a fim de melhor correlacionar e precisar a sucessão de terraços de uma região. Os mais importantes são: os estudos sedimentológicos, incluindo a composição do sedimento, gra- 
nulometria, sucessão vertical, evolução pedogenética, correlação altimétrica, datação, entre outros. Assim, do estudo dos terraços podem ser inferidas conclusões relativas aos paleoclimas e condições hidrológicas da bacia de drenagem.

A datação absoluta por meio de Luminescência Opticamente Estimulada (LOE) de material de origem de solos em diferentes níveis de terraços fluviais do Rio Mogi Guaçu em perfil topomorfológico anteriormente estudado por Perez Filho et al. (1980) em área da Fazenda Campininha, no município paulista de Mogi Guaçu permite avançar as discussões referentes ao condicionamento climático da dinâmica fluvial. Por meio destas datações procurou-se estabelecer relação entre o desenvolvimento dos terraços e oscilações climáticas ocorridas durante o final do Pleistoceno e o Holoceno. Assim, discutem-se e questionam-se as datações relativas realizadas pelos autores citados levando-se em conta o resultado das datações das formações superficiais (material de origem dos solos) feitas por meio de LOE, com 15 alíquotas de calibração no protocolo SAR.

\section{Área de estudo}

A Bacia Hidrográfica do Rio Mogi Guaçu (Figura 1) compreende uma área total de $17.460 \mathrm{~km}^{2}$, dos quais 14.653 km² estão localizados na porção nordeste do estado de São Paulo. Tem formato aproximadamente retangular e se estende no sentido sudoeste - noroeste. Zancopé e Perez Filho (2006) destacam que o Rio Mogi Guaçu nasce no Morro do Curvado, no município de sul-mineiro de Bom Repouso, numa altitude aproximada de $1.510 \mathrm{~m}$ e localizado entre as coordenadas $22^{\circ} 30^{\prime} \mathrm{S}$ e 460' W, na região da Serra da Mantiqueira, próximo ao limite interestadual São Paulo - Minas Gerais, no Sudeste Brasileiro. Após escoar longitudinalmente por aproximados $530 \mathrm{Km}$, deságua no Rio Pardo a 483 $\mathrm{m}$ acima do nível médio do mar entre as coordenadas $20^{\circ} 53^{\prime} \mathrm{S}$ e $48^{\circ} 11^{\prime} \mathrm{W}$, no NE do estado paulista.

A Fazenda Campininha localiza-se no município paulista de Mogi Guaçu, no médio-curso do Rio Mogi Guaçu, no contexto da Depressão Periférica Paulista, área com modelado de vertentes convexas e topos aplanados, identificado em Ross e Moroz (1997); sobre as rochas da Bacia Sedimentar do Paraná, com predomínio de arenitos finos, argilitos e folhelhos.

De acordo com Zancopé et al. (2009), mudanças climáticas também podem afetar a forma do perfil longitudinal, por influenciarem a magnitude e freqüência das vazões, sendo que o rio ajusta os processos de erosão, transporte e deposição e, conseqüentemente, a forma do perfil, para atender as novas condições do clima. Assim, o desenvolvimento de níveis de terraços fluviais teria relação direta com esses ajustes.

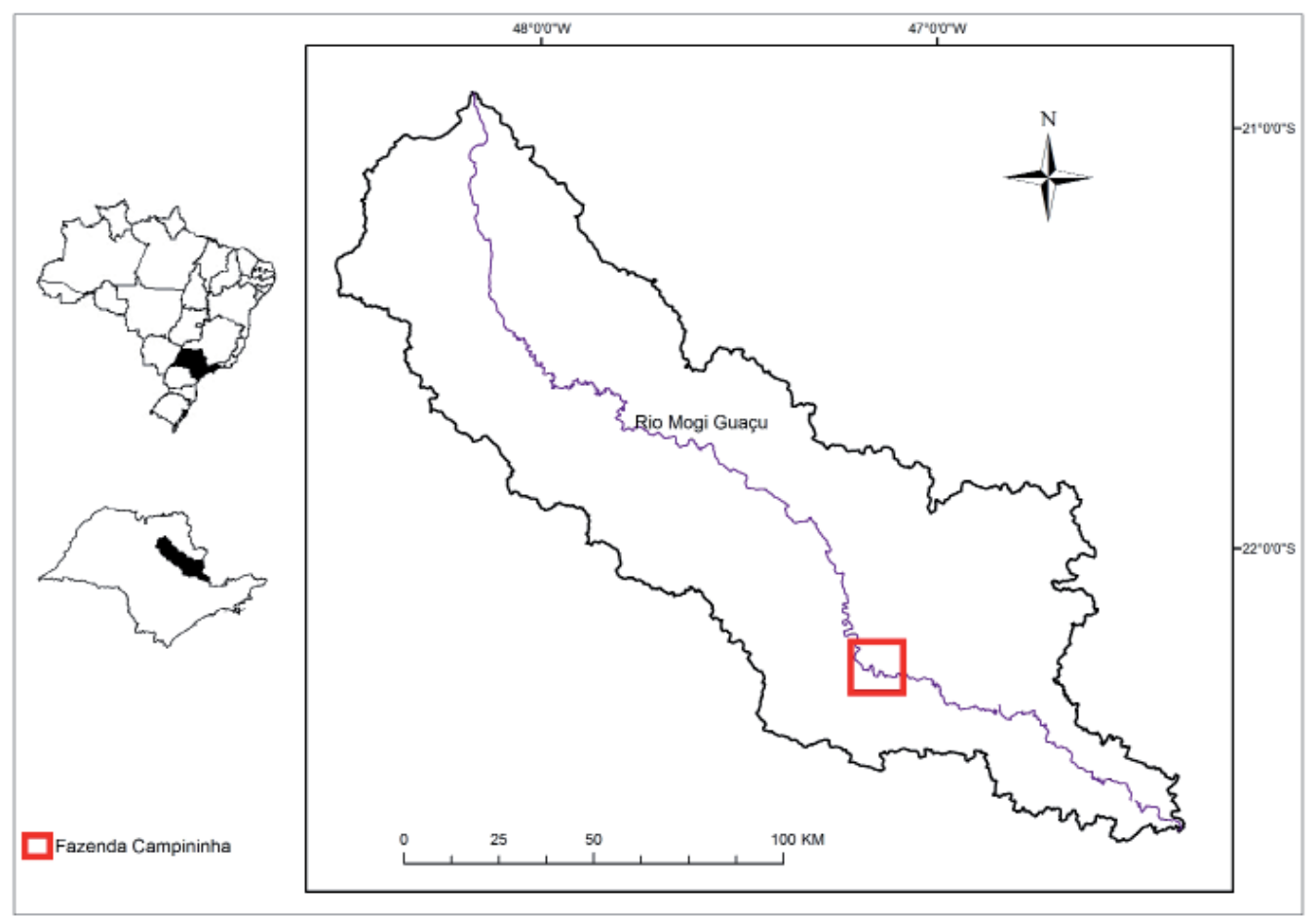

Figura 1 - Localização da Bacia Hidrográfica do Rio Mogi Guaçu e da Fazenda Campininha no município de Mogi Guaçu/SP. 
Zancopé e Perez Filho (2006) mostram que anomalias na forma do perfil longitudinal do Rio Mogi Guaçu têm relações com mudanças na morfologia do canal ao longo do seu curso e nos processos de migração dos meandros. Demonstraram também que as planícies fluviais localizadas na Fazenda Campininha apresentam canais de elevada sinuosidade e diferentes formas de relevo resultantes da migração do canal, como meandros abandonados e paleo-canais.

Tal anomalia no perfil do rio representaria um ajuste do perfil longitudinal por meio do entalhamento das rochas paleozóicas menos resistentes. Esse ajuste promoveria modificações na morfologia e sinuosidade do canal no trecho. O entalhamento promoveria encaixamento dos meandros num trecho seguinte e promoveria aumento do gradiente, causando aumento da energia de drenagem, conseqüente encaixamento da faixa meân- drica e aumento da sinuosidade.

Além disso, cita-se a influência das estruturas geológicas e feições estruturais da bacia na dinâmica fluvial e, consequentemente, no perfil longitudinal do Rio Mogi Guaçu, tendo as áreas de planícies fluviais relação com essas características.

\section{Metodologias}

Foram selecionados pontos de amostragem relacionados aos níveis de terraços e pedimento identificados por Perez Filho et al. (1980). O perfil topomorfológico A-B-C analisado por esses autores compreende um nível de encosta (ou pedimento) entre 574 e 577 metros de altitude, e três níveis de terraço (que estão, respectivamente, 5, 4 e 2 metros acima do leito atual do rio), além do aluvião recente (nível IV) (Figura 2).

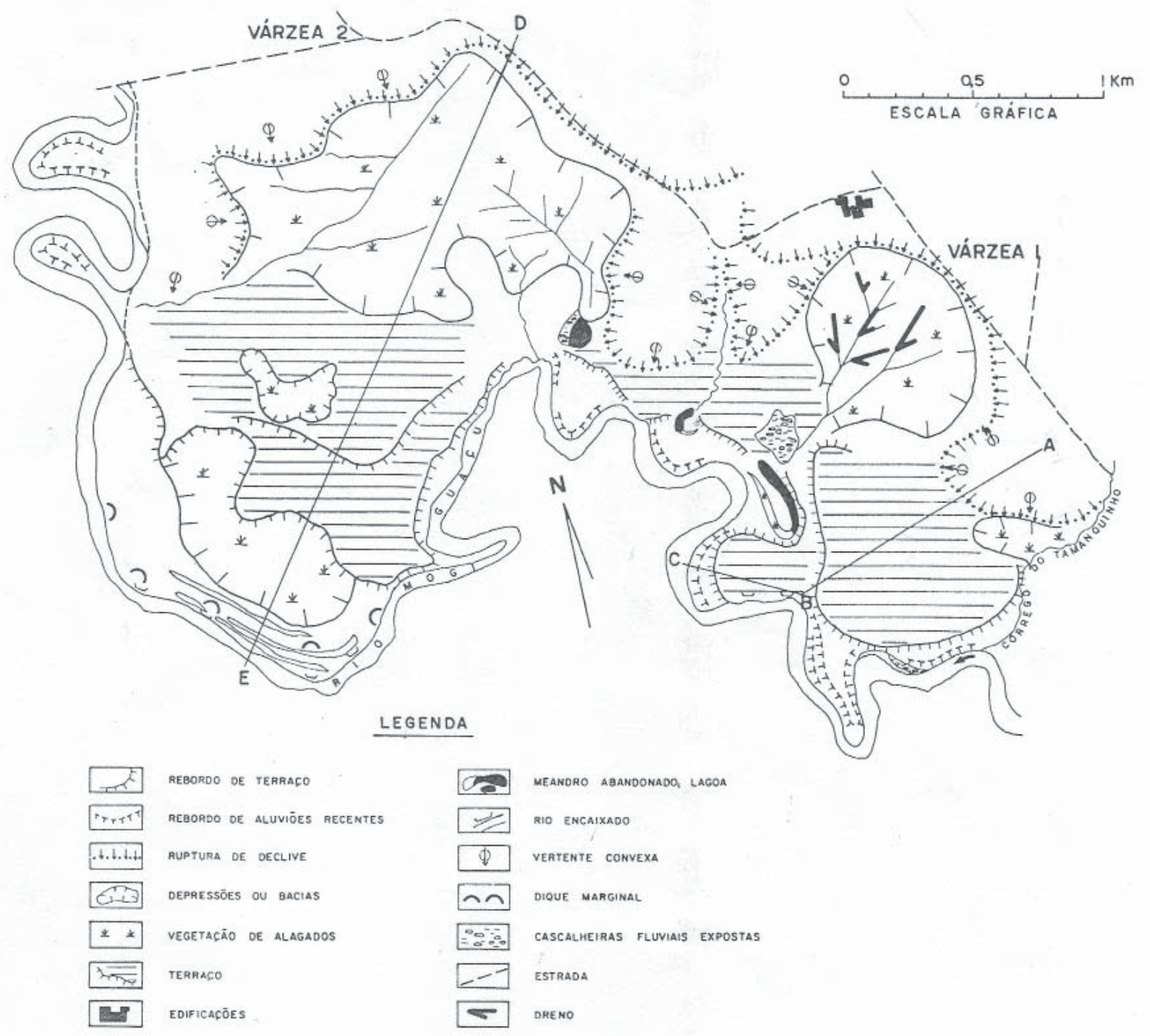

Figura 2 - Esboço geomorfológico de várzea do Rio Mogi Guaçu na Fazenda Campininha, Mogi Guaçu, SP (Fonte: Perez Filho et al., 1980). 
De acordo com Christofoletti (1974), terraços fluviais representam antigas planícies de inundação que foram abandonadas e, morfologicamente, surgem como patamares aplainados, de largura variada, limitados por uma escarpa em direção ao curso d'água. No caso de terraços compostos por materiais relacionados à antiga planície de inundação, são designados terraços aluviais. De acordo com o autor, esses terraços situam-se a determinada altura acima do curso do rio atual, que não tem mais capacidade para recobri-los em épocas de cheia. No perfil analisado por Perez Filho et al. (1980), os níveis I, II e III de terraço estão, respectivamente, 5, 4 e 2 metros acima do leito do rio. $\mathrm{O}$ abandono das planícies de inundação (preenchimento deposicional em vale previamente entalhado) pode ser explicado por oscilação climática, que provoca diminuição no débito com consequente formação de nova planície de inundação, em nível mais baixo, embutida na anterior. É possível também que grande parte da planície de inundação anterior, ou sua totalidade, possa ser removida antes ou durante a formação de nova planície, principalmente quando se trata de vales estreitos, sem potencial para desenvolvimento lateral. Há ainda a possibilidade de formação de terraço encaixado, ou planície de inundação em nível mais baixo acompanhada de nova fase erosiva sobre o embasamento rochoso do fundo do vale, como resultado de movimentos tectônicos, abaixamento do nível de base ou modificações no potencial hidráulico do rio.

Foram coletadas amostras de cobertura superficial nos níveis I, II e III de baixos terraços fluviais, e também no pedimento identificado pelos autores. A coleta de amostra se dá com o tubo de PVC limpo e de cor escura (para evitar entrada de luz solar). O tubo de PVC, com aproximadamente 60 centímetros de comprimento e seis centímetros de diâmetro foi enterrado horizontalmente a uma profundidade de 60 a $80 \mathrm{~cm}$, utilizando-se de um martelo de borracha para bater na ponta exposta e para que ele fosse completamente enterrado. Depois de o tubo estar completamente preenchido, a ponta exposta é fechada com a tampa (cap de PVC) de forma que não haja mais exposição à luz. O tubo é cuidadosamente retirado do solo, envolvido em saco plástico preto, e a ponta retirada também é fechada. Lacraram-se as pontas com fita plástica adesiva, e o tubo recebe o nome do ponto de coleta, indicando-se também a direção de inserção do tubo no solo, seguindo recomendações do laboratório de análise. As amostras de solo foram submetidas à datação por LOE (Luminescência Opticamente Estimulada) no laboratório Datação Comércio e Prestação de Serviços LTDA, em São Paulo, SP.

\section{Datação absoluta de sedimentos por LOE}

Segundo Corrêa et al. (2002), a vantagem da datação absoluta de material sedimentar por LOE sobre os demais procedimentos de datação absoluta de sedimentos recentes, como o C14, por exemplo, está no fato de este explorar uma propriedade física - a luminescência inerente aos minerais encontrados no próprio depósito, principalmente o quartzo e os feldspatos. Assim, a LOE se converte em método de datação absoluta de eventos deposicionais. Pelo fato da abrangência temporal do método da LOE ir desde de cerca de 100 anos ap. até 1Ma, dependendo dos níveis de saturação do material analisado, ele tem grande utilidade para a datação de eventos deposicionais ocorridos ao longo do Quaternário. Podem ser datados desde eventos climáticos regionais de grande magnitude (mudanças nos padrões de circulação regional), eventos tectônicos que impactaram a rede de drenagem (inversões e capturas por soerguimento das cabeceiras), até episódios erosivos recentes, desencadeados por alterações nos padrões de uso do solo.

\section{Resultados e Discussões}

Os resultados da datação absoluta por LOE são apresentados em número de anos antes do presente correspondente à última exposição do material sedimentar à luz solar, com uma faixa de variação ou erro. É utilizado por padrão internacionalmente reconhecido o protocolo SARs com 15 alíquotas, o que garante maior precisão aos resultados obtidos.

As datações absolutas por meio de LOE realizadas nas amostras dos pontos escolhidos no perfil A-B-C segundo Perez Filho et al. (1980) apresentaram os seguintes resultados: cobertura superficial com aproximadamente 3.650 anos sobre o pedimento descrito no perfil; material superficial com idade aproximada de 1.900 anos sobre o terraço fluvial de nível I; cobertura superficial com aproximadamente 1.150 anos no terraço fluvial de nível II; e cobertura superficial depositada há 630 anos recobrindo o baixo terraço fluvial de nível III (Figura 3 e Tabela 1). 


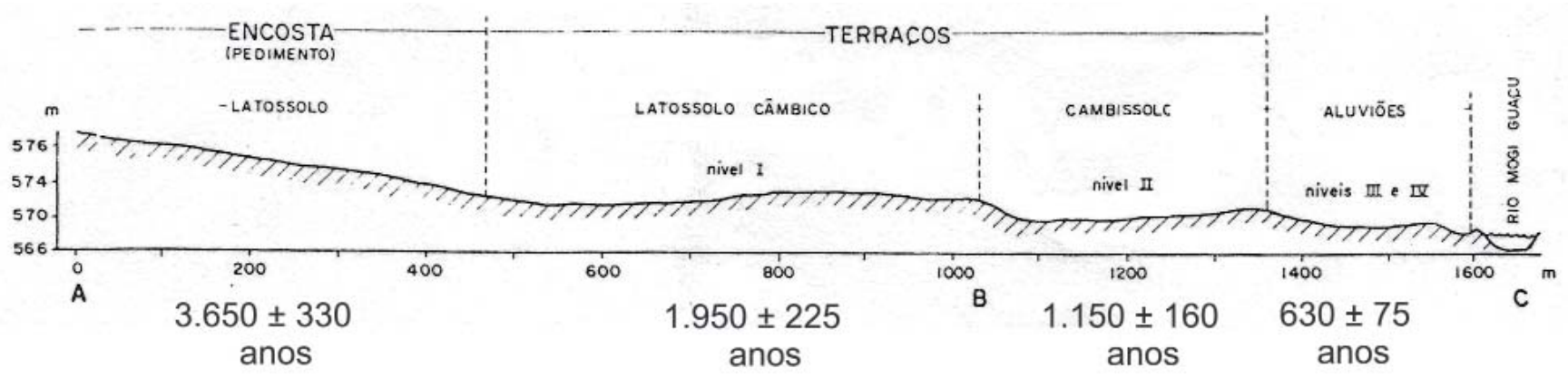

Figura 3 - Perfil topomorfológico A-B-C e resultados de datação absoluta por LOE das coberturas superficiais em distintos níveis de baixos terraços e pedimento (Fonte: adaptado de Perez Filho et al., 1980).

Tabela 1: Localização de pontos de coleta e resultados de datação absoluta por LOE do material de cobertura de cada nível de baixo terraço do perfil analisado no Rio Mogi Guaçu na Fazenda Campininha, Mogi Guaçu/SP (Fonte: Perez Filho et al., 1980).

\begin{tabular}{|c|c|c|c|}
\hline Nível Terraço & Altitude (m) & Localização (Graus) & Idade (Anos) \\
\hline \multirow{2}{*}{ I } & 574 & $\begin{array}{l}22^{\circ} 29^{\prime} 27.33^{\prime \prime} \mathrm{S} \\
47^{\circ} 15^{\prime} 22.81^{\prime} \text { O }\end{array}$ & $1.900 \pm 225$ \\
\hline \multirow{2}{*}{ II } & 572 & $\begin{array}{l}22^{\circ} 29^{\prime} 04.40^{\prime \prime} \mathrm{S} \\
47^{\circ} 16^{\prime} 20.96^{\prime} \text { O }\end{array}$ & $1.1150 \pm 160$ \\
\hline \multirow{2}{*}{ III } & 570 & $\begin{array}{l}22^{\circ} 29^{\prime} 08.97^{\prime} \text { S } \\
47^{\circ} 16^{\prime} 09.27^{\prime} \text { O }\end{array}$ & $630 \pm 75$ \\
\hline
\end{tabular}

Levando-se em consideração os resultados das datações nos três níveis de terraço, é possível pressupor a existência de uma relação entre as idades atribuídas a eles e a pulsos de oscilações climáticas. Com base na literatura, a incisão ou entalhe dos canais verifica-se em períodos de condições climáticas mais úmidas, enquanto que a constituição do terraço corresponderia a períodos de clima mais seco. Assim sendo, a partir das datações absolutas obtidas, pode-se considerar o predomínio de um período seco há aproximadamente 1.900 anos, seguido de um período úmido, que causou a diferenciação dos níveis de terraço com entalhamento do canal fluvial, e possibilitou o desenvolvimento das características pedológicas dos solos, sendo este período seguido por outra fase seca, predominando há aproximadamente 1.150 anos. Este ciclo poderia ter se repetido na formação do nível III de terraço, há 630 anos.

Na Bacia Hidrográfica do Mogi Guaçu, Perez Filho (1987) correlaciona os níveis de terraço entre 560 e 580 metros ao Pleistoceno Superior (T1 e T2). O resultado das datações absolutas realizadas, no entanto, permite levantar discussões quanto a essa associação. Os materiais superficiais datados entre 1.150, 1.900 e 630 anos corresponderiam, na escala de tempo geológico, a um período muito mais recente.

Apesar de Penteado (1969) generalizar um período quente e úmido para a história recente da região, é possível considerar a existência de aletrações climáticas intermediárias, para até três fases mais secas, nos períodos correspondentes as idades dos materiais de origem dos solos dos níveis I, II e III de terraços. A análise do período recente, no entanto, não pode desconsiderar que atividades neotectônicas possam ter existido e que, alterando níveis de base locais, tenham causado alterações na dinâmica do rio. O resultado da associação desses fatores poderia resultar nas condições atuais do terraço analisado.

As datações absolutas realizadas por meio de LOE confirmam, no entanto, a sequência da datação relativa demonstrada pelos autores Perez Filho et al. (1980) com a seguinte ordem: o material de origem do solo do terraço nível III seria mais novo do que material que recobre o terraço nível II, e este mais novo do que o sedimento encontrado no terraço nível I, mais distante do canal fluvial. A atribuição de idades por tais autores baseou-se em parâmetros granulométricos e químicos 
de amostras de solo de cada nível. Perez Filho et al. (1980, p.186) explicam que

Para relacionamento de propriedades do solo com idade das superfícies escolheu-se características do solo que indicam índice de intemperismo [...]: relação silte/argila e capacidade de troca de argila. Solos mais intemperizados normalmente apresentam valores menores desses parâmetros.

No perfil escolhido, a drenagem pouco varia e, nos níveis de terraço, possivelmente foram depositados sedimentos semelhantes transportados pelo Rio Mogi Guaçu. É possível apresentar, portanto, a idéia de evolução sequencial das planícies fluviais.

Quanto ao nível que Perez Filho et al. (1980) classificaram como pedimento, a uma altitude de aproximadamente 600 metros, encontrou-se solo com idade de aproximadamente 3.650 anos, permitindo-se estabelecer uma nova relação com uma oscilação seca mais recente estabelecida por Penteado (1969) em datação relativa. No entanto, tal literatura relaciona a gênese dos pedimentos inferiores da região a um período próximo ao Pleistoceno Superior.

\section{Conclusões}

No contexto da Bacia Hidrográfica do Rio Mogi Guaçu, mais especificamente nas área analisada da Depressão Periférica, é possível supor a existência de pulsos de oscilações climáticas de períodos mais quentes e secos.

No caso dos terraços fluviais estudados na Fazenda Campininha, as datações permitiram inferir oscilações climáticas secas num período pré-atual, com desenvolvimento de níveis de terraço, seguidas de oscilações mais úmidas, com constituição de ambiente que favoreceu novo entalhe do canal fluvial. Os terraços de níveis I e II apresentam cobertura vegetal de Cerrado e o nível III, mais recente, de acordo com a datação realizada, demonstraria predomínio de mais um período seco há aproximadamente 630 anos. O nível de aluviões (nível IV) proposto no perfil de Perez Filho et al. (1980) com cobertura vegetal de floresta densa, e entalhamento do canal fluvial, confirmam a proposta de que o período atual corresponde a oscilação mais quente e úmida.

As correlações e cenários aqui apresentados en- volvem, no entanto, cautela quanto à escala espacial envolvida na análise. A partir de tal estudo propõe-se a expansão do mesmo abrangendo níveis de baixos terraços em bacias hidrográficas da Depressão Periféria e do Planalto Ocidental Paulista.

O estudo realizado permite validar idéias convergentes às de Queiroz Neto (1982), autor que também expõe o conceito de que a sucessão de ciclos bioclimáticos e morfogenéticos mais secos e mais úmidos teria capacidade de comandar, em parte, a evolução das paisagens. Além disso, os resquícios das condições bioclimáticas pretéritas permanecem no contexto geomorfológico atual, como testemunhas dessa evolução.

As datações absolutas, independentemente dos processos envolvidos na formação da planície fluvial analisada, demonstram que a dinâmica geomorfológica sugerida pela literatura para o caso do Rio Mogi Guaçu estão de acordo com a cronologia aqui estabelecida. Os dados recém adquiridos complementam esquema evolutivo anteriormente proposto, e estão dentro dos parâmetros de datação divulgados para outros rios do estado de São Paulo, e em outras regiões.

\section{Agradecimentos}

Agradecemos à FAPESP (Fundação de Amparo à Pesquisa do Estado de São Paulo) pelo financiamento da bolsa de doutorado durante a qual se desenvolveu a pesquisa realizada.

Agradecemos ao Espaço da Escrita - Coordenadoria Gera da Universidade - UNICAMP - pelos serviços linguísticos prestados.

\section{Referências Bibliográficas}

AB'SABER, A. N. A depressão periférica paulista: um setor das áreas de circundesnudação pós-cretácica na Bacia do Paraná. Geomorfologia, São Paulo, v. 15, n. 1, p.1-15, 1969.

BIGARELLA, J. J.; MOUSINHO, M. R.; SILVA, J. X. da. Processes and environments of the Brazilian quaternary. Curitiba: Imprensa da Universidade do Paraná, 1965. 71 p.

BIGARELLA, J. J.; DOS SANTOS, G. F.; DE PAULA HERRMANN, M. L.; DE CARVALHO, S. M. C.; MENDONÇA, M. Estrutura e Origem das Paisagens Tropicais e Subtropicais - Vol. I., Florianópolis: UFSC, 1994.

BRIDGE, J. S. Rivers and Floodplains: Forms, Processes and 
Sedimentary Record. Oxford: Blackwell Publishing Limited, 2003.

CASSETI, V. Geomorfologia. Goiânia: [S.I.], 2005. Disponível em: <http://www.funape.org.br/geomorfologia>. Acesso em: 22 out. 2014.

CHRISTOFOLETTI, A. Geomorfologia. São Paulo: Edgard Blucher. 1974.

CHRISTOFFOLETI, A. Geomorfologia fluvial. São Paulo: Edgard Blucher. 1981.

CORREA, A. C. B.; ESPÍNDOLA, C. R.; MENDES, I. A. Avaliação da dinâmica geomorfológica dos compartimentos elevados do Planalto da Borborema, Nordeste do Brasil, com base no método de datação da (LOE) Luminescência Opticamente Estimulada. In: MENDES, I. A.; GERARDI, L. de O. (Org.). Do natural, do Social e de suas interações: visões geográficas. Rio Claro: Programa de Pós-graduação em Geografia UNESP, 2002. p. 21-34.

DAMUTH, J. E.; FAIRBRIDGE, R. W. Equatorial atlantic deepsea arkosic sands and ice-age aridy in tropical South America. Geological Society of America Bulletin, n. 81, 1970.

PENTEADO, M. M. A Bacia de Sedimentação de Rio Claro - São Paulo. Revista Geographica da Soc. Geog. de Lisboa, Lisboa, v. 17, n. 1, p.76-88, 1969.

PENTEADO, M. M. Fundamentos de Geomorfologia. Rio de Janeiro: IBGE, 1980.

PEREZ FILHO, A.; DONZELLI, J. L.; LEPSCH, I. F. Relação Solos-Geomorfologia em Várzea Do Rio Moji-Guaçu (SP). Revista Brasileira de Ciência do Solo, Viçosa, p.181-187, 1980.
PEREZ FILHO, A. Relações solo-relevo na porção centrooriental do Estado de São Paulo. 1987. 183 f. Tese (Doutorado) - Curso de Geografia, Universidade de São Paulo, São Paulo, 1987.

QUEIROZ NETO, J. P. Solos da Região dos Cerrados e Suas Interpretações. Revista Brasileira de Ciência do Solo, Campinas, v.6, n.3, p.1-12, 1982.

ROSS, J. L. S.; MOROZ, I. C. Mapa Geomorfológico do Estado de São Paulo, escala 1:500.000. Geografia-FFLCH-USP, IPT/FAPESP, São Paulo, vol. 1, 1997.

SUGUIO, K. Geologia do Quaternário e mudanças ambientais: (passado + presente = futuro?). São Paulo: Paulo’s Comunicação e Artes Gráficas, 1999.

SUGUIO, K. Geologia do Quaternário e Mudanças Ambientais. São Paulo: Oficina de Textos, 2010.

SUGUIO, K.; BIGARELLA, J. J. Ambiente Fluvial. Curitiba: Editora Universidade Federal do Paraná; ADEA, 1979.

ZANCOPÉ, M. H. de C.; PEREZ FILHO, A.; CARPI JUNIOR, S. Anomalias no perfil longitudinal e migração dos meandros do Rio Mogi Guaçu. Revista Brasileira de Geomorfologia, Uberlândia, v. 10, n. 1, p.31-42, 2009.

ZANCOPÉ, M. H. de C.; PEREZ FILHO, A. Considerações a Respeito da Distribuição das Planícies Fluviais do Rio Mogi Guaçu. Revista Brasileira de Geomorfologia, Uberlândia, v. 7, n. 1, p.65-71, 2006.

WOLMAN, M. G.; LEOPOLD, L. B. Flood Plains. In: DURY, G. H. (Org.). Rivers and rivers terraces. Londres: Geographical Readings, 1970. 